Turkish Journal of Thoracic and Cardiovascular Surgery 2018;26(2):324-325

http://dx.doi.org/doi: 10.5606/tgkdc.dergisi.2018.15461

Interesting Image / IIginç Görüntü

\title{
A rare collateral pathway
}

\author{
Nadir bir kollateral dolaşım
}

Çetin Geçmen ${ }^{\circ}$, Muzaffer Kahyaoğlu $\bullet$, Akın İzgi $\odot$

Department of Cardiology, Kartal Koşuyolu Yüksek intisas Training and Research Hospital, istanbul, Turkey

A 54-year-old male patient was admitted to our cardiology outpatient with stable angina pectoris. He also suffered from type 2 diabetes and hypertension. The stent was implanted to the circumflex artery one year ago. Electrocardiography showed non-specific T-wave changes. Laboratory test results were also within normal limits. We performed exercise stress test and detected $1.5 \mathrm{~mm}$ horizontal ST segment depression in the inferior lead. Selective coronary angiography was performed and left coronary angiography showed chronic total occlusion (CTO) of the left circumflex artery (LCx) in the left and right caudal oblique view and critical lesion of distal left anterior descending artery (Figure 1a, b). Right coronary angiography revealed no lesion and also good epicardial collateral to the LCx from the right coronary artery (RCA) sinoatrial nodal branch (Figure 1c, d). The patient was discharged with medical treatment.

Coronary CTO, commonly seen in patients with chronic stable angina, is characterized by the presence of atherosclerotic plaque resulting in complete or near complete occlusion of coronary artery for greater than three-month duration. ${ }^{[1]}$ The myocardial territory supplied by CTO tends to form well developed collaterals from a donor artery in the course of time. ${ }^{[2]}$ Chronic total occlusion of the LCx has several collateral pathways as diagonal artery (D) to obtuse marginal artery $(\mathrm{OM})$, posterior left ventricular branch (PLV) to atrioventricular circumflex (AVCx), posterior descending artery (PDA) to $\mathrm{OM} \cdot{ }^{[3]}$ In the largest analysis of collateral circulation anatomy in a population of patients with CTOs reported by McEntegart, ${ }^{[3]}$ a total of 120 collaterals were identified for LCx CTOs and 28 (32.2\%) of all LCx CTOs had collaterals from the D to OM branch of the LCx collaterals, while $18(20.7 \%)$ had PLV to AVCx collaterals. Fifteen (17.2\%) had
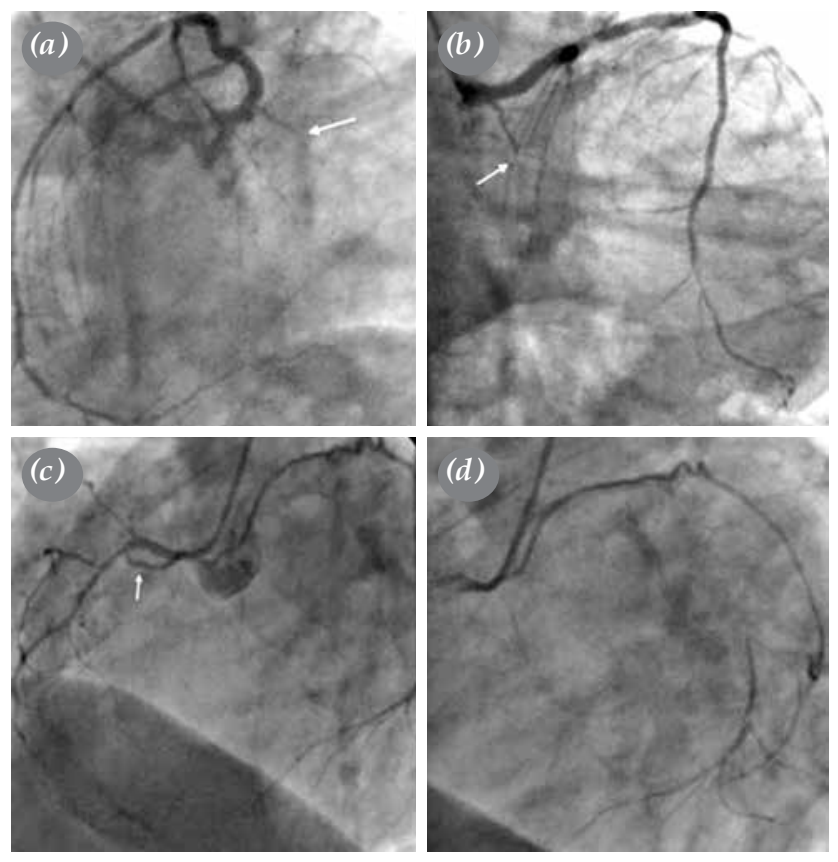

Figure 1. (a) Left coronary angiography showing CTO of the LCx (arrow) in the left caudal oblique view. (b) Left coronary angiography showing CTO of the LCx (arrow) in the right caudal oblique view. (c, d) Right coronary angiography showing good epicardial collateral to the LCx from the RCA sinoatrial nodal branch (arrow).

CTO: Chronic total occlusion; LCx: Left circumflex artery; RCA: Right coronary artery.

Received: October 24, 2017 Accepted: January 29, 2018 Published online: April 30, 2018

Correspondence: Çetin Geçmen, MD. Kartal Koşuyolu Yüksek İhtisas Eğitim ve Araştırma Hastanesi, Kardiyoloji Kliniği, 34865 Cevizli, İstanbul, Turkey. Tel: +90 216 - 5001500 e-mail: koronerr@hotmail.com 
bridging collaterals and $10(11.5 \%)$ had proximal OM branch to more distal OM branch collaterals (autocollaterals). In addition, eight (9.2\%) had PDA to OM collaterals. In this large-scale study, the collateral pathway originating from the sinoatrial nodal branch of the RCA was not observed. Collateral pathway originating from the sinoatrial nodal branch is quite rare. Herein, we report a rare collateral pathway to the LCx from the sinoatrial nodal branch.

\section{Declaration of conflicting interests}

The authors declared no conflicts of interest with respect to the authorship and/or publication of this article.

\section{Funding}

The authors received no financial support for the research and/or authorship of this article.

\section{REFERENCES}

1. Shah PB. Management of coronary chronic total occlusion. Circulation 2011;123:1780-4.

2. Bardají A, Rodriguez-López J, Torres-Sánchez M. Chronic total occlusion: To treat or not to treat. World J Cardiol 2014 26;6:621-9.

3. McEntegart MB, Badar AA, Ahmad FA, Shaukat A, MacPherson $M$, Irving $J$, et al. The collateral circulation of coronary chronic total occlusions. EuroIntervention 2016;11:e1596-603. 